\title{
Determinants of self-paid rotavirus vaccination status in Kanazawa, Japan, including socioeconomic factors, parents' perception, and children's characteristics
}

\author{
Megumi Hara ${ }^{1 *}$ (D, Rie Koshida ${ }^{2}$, Kaoru Araki $^{3}$, Masahide Kondo ${ }^{4}$ and Yoshio Hirota ${ }^{5,6}$
}

\begin{abstract}
Background: Japan's National Immunization Program does not cover rotavirus vaccine and no government subsidies are available. This study aimed to measure the uptake of and determinants that influenced self-paid rotavirus vaccination, including socioeconomic status and relative poverty.

Methods: We conducted a cross-sectional study at health check-ups for all children aged 18 months in Kanazawa, Japan, between December 2017 and July 2018. Community nurses collected information on self-paid vaccination history, parents' perceptions of and recommendations for rotavirus vaccine, and socioeconomic status in interviews using a unified questionnaire. We used multivariable logistic regression to assess vaccine uptake and possible determinants.

Results: In total, 1282 participants were enrolled. The estimated rotavirus vaccine coverage was $72.9 \%$. Perceptions that rotavirus gastroenteritis was serious and that the rotavirus vaccine was effective, pediatricians' recommendations, information from the city office, magazine and Internet articles, and higher parental education level were associated with higher rotavirus vaccine uptake. Lower household income was associated with decreased rotavirus vaccine uptake. Vaccine expense, fear of adverse reactions to the vaccine, number of household members and siblings, and children's characteristics were not correlated with rotavirus vaccination. Poverty was associated with decreased rotavirus vaccine uptake, even after adjustment for other determinants (adjusted odds ratio 0.49 , 95\% confidence interval: 0.26-0.90).

Conclusion: Parents' perceptions, socioeconomic status, relative poverty, and pediatricians' recommendations are determinants of vaccination. This study suggests that appropriate information about rotavirus vaccine, subsidies for those of lower socioeconomic status, and national recommendations are necessary to achieve higher coverage.
\end{abstract}

Keywords: Rotavirus vaccine, Self-paid vaccine, Coverage, Socioeconomic status

\footnotetext{
* Correspondence: harameg@cc.saga-u.ac.jp

${ }^{1}$ Department of Preventive Medicine, Faculty of Medicine, Saga University,

5-1-1 Nabeshima, Saga 849-8501, Japan

Full list of author information is available at the end of the article
}

(c) The Author(s). 2020 Open Access This article is licensed under a Creative Commons Attribution 4.0 International License, which permits use, sharing, adaptation, distribution and reproduction in any medium or format, as long as you give appropriate credit to the original author(s) and the source, provide a link to the Creative Commons licence, and indicate if changes were made. The images or other third party material in this article are included in the article's Creative Commons licence, unless indicated otherwise in a credit line to the material. If material is not included in the article's Creative Commons licence and your intended use is not permitted by statutory regulation or exceeds the permitted use, you will need to obtain permission directly from the copyright holder. To view a copy of this licence, visit http://creativecommons.org/licenses/by/4.0/. The Creative Commons Public Domain Dedication waiver (http://creativecommons.org/publicdomain/zero/1.0/) applies to the data made available in this article, unless otherwise stated in a credit line to the data. 


\section{Background}

Rotavirus has strong infectivity. It is difficult to prevent infection by hand washing or hygiene, and it is the leading etiology for diarrhea mortality among children aged 5 years and under [1]; therefore, the World Health Organization (WHO) recommended inclusion of rotavirus vaccines in national immunization programs (NIP) in 2009 [2]. Two live oral vaccines are internationally available: a single strain human rotavirus vaccine (Rotarix ${ }^{\oplus}$ GlaxoSmithKline Biologicals, Rixansart, Belgium) [3] and a human-bovine reassortant vaccine (RotaTeq ${ }^{\oplus}$, Merck \& Co., Inc., Rahway, NJ, USA) [4]. Four additional rotavirus vaccines are licensed, two in India (Rotavac and Rotasiil), one in China (Lanzhou lamb rotavirus vaccine), and one in Vietnam (RotavinM1) [5]. However, rotavirus vaccine is not part of the NIP in many countries, especially in Asia [6].

In the US, there was a well-known risk for intussusception associated with an earlier rotavirus vaccine (RRV-TV, Rotashield, Wyeth Laboratories), which was approved in 1998 and stopped in 1999 [7]. Qualitative research reported that safety concerns and lack of knowledge about rotavirus gastroenteritis (RVGE) were barriers to vaccination when the new rotavirus vaccine (RotaTeq ${ }^{\circledR}$ ) was approved in 2006 [8]. In Canada, rotavirus vaccination is recommended for all infants, although not all provinces have publicly funded programs. A Canadian study reported that increased knowledge and more positive attitudes toward the vaccine among parents increased the coverage of rotavirus vaccine [9]. Few previous studies have evaluated the influence of parents' socioeconomic factors on vaccine uptake, although one study reported lower parental socioeconomic status and lower parental concerns about vaccine were determinants of not being vaccinated [10].

In Japan, Rotarix ${ }^{\circledR}$ and RotaTeq ${ }^{\oplus}$ became available on the private market in November 2011 and July 2012, respectively. Because of the high effectiveness of these vaccines $[11,12]$ and their impact on reducing hospitalization from RVGE [13-16], rotavirus vaccine will be included in Japan's NIP in October 2020; however, vaccination is self-paid at present. Additionally, vaccination coverage in Japan is unclear because Japan has no vaccination registry. A previous study in Japan reported that higher annual household income and positive maternal opinion of voluntary vaccination were associated with increased voluntary vaccination uptake, whereas a larger number of siblings was associated with decreased voluntary vaccination uptake [17]. However, that study did not evaluate specific determinants of rotavirus vaccination. As of May 2020, rotavirus, mumps, and influenza vaccines are self-paid vaccines for children in Japan. Newer vaccines, such as rotavirus vaccine, are more expensive compared with those that have been used for many decades, such as the mumps and influenza vaccines. In Japan, the cost of vaccination includes the doctor's technical fee for administering the vaccine (around US \$33 per dose) [18], meaning the cost per full course of rotavirus vaccine is around US $\$ 283$. This cost is higher than the price per vaccination course elsewhere, with costs ranging from approximately US $\$ 0.50$ in GAVI-eligible countries to US \$185-\$226 in the US [19]. Conversely, the costs (including doctor's technical fee for administration) for the first dose of mumps vaccine and first two doses of influenza vaccine were reported at US $\$ 30-\$ 70$ and US $\$ 40-\$ 80$, respectively [20]. The high cost of the rotavirus vaccine may be a barrier to vaccination. However, the impact of socioeconomic factors on rotavirus vaccination uptake has not been evaluated in Japan, especially considering household income.

The impact of household income on self-paid vaccine uptake may differ according to the number of siblings. Therefore, equivalized household income, which is the household income divided by the number of household members, is useful for evaluating economic status and self-paid vaccine uptake. Relative poverty, which is commonly defined as an equivalized household income less than $50 \%$ of the national median, is also associated with children's health, including infant mortality, low birth weight, not having immunizations, child mortality due to unintentional injuries, childhood obesity, and mental health problems [21]. According to the Comprehensive Survey of Living Conditions conducted by Japan's Ministry of Health, Labour and Welfare, the relative poverty rate increased from $13.5 \%$ in 1991 to $15.7 \%$ in 2015 [22]. Previous studies reported associations between socioeconomic deprivation and vaccine uptake [23, 24]. Therefore, it is necessary to evaluate the influence of relative poverty on rotavirus vaccine uptake.

This study aimed to measure the uptake of rotavirus vaccine and determinants that influenced self-paid rotavirus vaccination, including socioeconomic factors, relative poverty, parents' perceptions, and children's characteristics.

\section{Methods}

\section{Study design and setting}

This cross-sectional study was conducted at the 18month child health check-up in Kanazawa, Japan, between December 2017 and July 2018. Kanazawa is the largest city in Japan's Hokuriku region. In 2018, the total population was about 465,000 people and there were around 3800 births. The Japanese government provides a nationwide continuum of maternal, newborn, and child healthcare, the central component of which is the maternal and child health handbook [25]. When pregnant women register, the local government provides them 
with a maternal and child health handbook; all services then start and follow a standard schedule. Pregnant women bring the handbook to their maternity clinic of choice for antenatal care, and their doctor records antenatal care results for them and their fetus in the handbook. After giving birth, all data regarding childbirth are recorded in the handbook, and mothers receive a birth certificate from the doctor that they take to local government to register the birth. Local governments then provide all registered infants with health information, healthcare advice, and vouchers for child health checkups and immunizations that are included in the NIP. The main contents of the maternal and child health handbook are described in detail elsewhere [26]. Child health and development check-ups (birth to age 6 years) and immunization status are also recorded in the handbook, regardless of whether they are included in the NIP. Local governments provide health check-ups for all children aged 18 months under the Maternal and Child Health Act. Kanazawa has three welfare and health centers that provide health check-ups for all children aged 18 months. The annual reports of the health and welfare services for children in Kanazawa indicate that the participation rate in health check-ups for children aged 18 months is around 98.9\% [27].

At the time of the children's health check-up, trained community nurses informed parents about this study and obtained consent for study participation. Then, parents were interviewed using a unified questionnaire that investigated factors that potentially influence rotavirus vaccine uptake. The questionnaire covered parents' perceptions about RVGE and the rotavirus vaccine, recommendations received or information obtained about rotavirus vaccine, and socioeconomic factors (such as number of household members and siblings, parental age and education level, mothers' employment). Additionally, data were collected on the child's birth weight, birth order, underlying diseases (food allergies, atopic dermatitis, nasal allergy, asthma, heart disease, and respiratory disease), daycare service use, and vaccination status for self-paid vaccines (including rotavirus, mumps, and influenza vaccines). Immunization status was ascertained from the maternal and child health handbook, in which all vaccination history must be recorded in Japan as per the Maternal and Child Health Act.

To examine whether relative poverty resulted in a $50 \%$ reduction of rotavirus vaccine uptake, a significant effect size of $50 \%$ and assuming vaccination uptake of $50 \%$, a percentage of factors associated with vaccination among unvaccinated subjects of $20 \%$, two-sided significance of 0.05 , and power of 0.8 , this study required 1124 participants.

\section{Definition and estimation of rotavirus vaccine coverage}

Ensuring that vaccination indicators (such as vaccine coverage and uptake) are clearly and consistently defined is important for effective communication of outcomes [28]. According to the US Centers for Disease Control and Prevention, childhood vaccination coverage is defined as the percentage of children in the target population who received a dose of a recommended vaccine [29]. Vaccine uptake is most commonly defined as the absolute number of people who received a specific dose; that is, the numerator in the vaccine coverage calculation. In Japan, rotavirus vaccine is recommended to start at 2 months of age and should be completed before 6 months; therefore, all children in this study had passed the recommended age range. We defined vaccine uptake as the number of children that received at least one dose of rotavirus vaccine. To estimate vaccination coverage, we calculated the proportion of self-reported rotavirus vaccine uptake and that of record-confirmed rotavirus vaccine uptake among children whose parents participated in this survey.

\section{Evaluating equivalent household income and relative poverty rate}

We recorded annual household income using five categories: less than $12,000,000 ; 12,000,000-\backslash 3,999,999$; $\backslash 4,000,000-\backslash 5,999,999$; $\backslash 6,000,000$ or more; and unknown. To estimate the mid-point of an open-ended income category, we used formulas described by Parker et al. [30] These formulas are based on Pareto's law of income distribution, which states that the logarithm of the percentage of units with an income in excess of a certain value is a negatively sloped linear function of the logarithm of that value. According to this theory [30], Celeste et al. defined the median income for the top-coded category $=10^{\wedge}(0.301 / \mathrm{v}) *(\mathrm{X})$, where $\mathrm{X}=$ lower value of the top-coded/open-ended category and $\mathrm{v}=\mathrm{c}-\mathrm{d} / \mathrm{b}-\mathrm{a}$. Where $\mathrm{a}=$ the $\log$ of the lower limit of the interval preceding the top-coded/ open-ended category; $\mathrm{b}=\log$ of the lower limit of the top-coded/open-ended category; $\mathrm{c}=$ the $\log$ of the sum of the frequencies in the top-coded category and the category preceding it; and $\mathrm{d}=$ the $\log$ of the frequencies in the top-coded category [31].

We equivalized household income using the square root of household scale, which means that household income was divided by the square root of household size [32]. For example, a household of four persons has needs twice as large as one composed of single person. The relative poverty rate was defined as the proportion of children with an equivalent household income less than $50 \%$ of the median of all surveyed children, following the definition of the Organisation for Economic Cooperation and Development (OECD) [33]. 


\section{Statistical analysis}

We first assessed correlations in parents' perception of rotavirus vaccine and RVGE, socioeconomic factors, and children's characteristics between vaccinated and unvaccinated children. Odds ratios (OR) and 95\% confidence intervals $(\mathrm{CI})$ were calculated using a univariate logistic regression model. Next, multiple logistic regression analysis was performed to investigate correlations between rotavirus vaccination status and potentially influential factors. Because birth order, number of siblings, and number of household members are highly correlated, we only included the number of siblings in the multivariable model. In Model 1, we adjusted for siblings $(\geq 2$ or $<2$ [reference]), mother's age $(<30$ years or $\geq 30$ years [reference]), parental educational level of university or above (yes/no [reference]), and household income below 14 , 000,000 (yes/no [reference]). In Model 2, we further adjusted for perceptions of RVGE, vaccine effectiveness, pediatrician recommendation, and information from city papers, magazines, and the Internet. For the equivalent income and relative poverty rate analyses, we excluded cases where data for household income and household size were not available, and performed additional analyses of the association between relative poverty status and self-paid vaccine uptake using complete data. Median household equivalent income was compared by rotavirus vaccine uptake status using the Mann-Whitney U-test. We evaluated associations between relative poverty and rotavirus vaccine uptake and uptake of other self-paid vaccines using multiple logistic regression analysis with adjustment for possible confounders. Parents' education level was entered into Model 1. Model 2 was further adjusted for parents' perceptions, recommendation, and information, which were significantly correlated with rotavirus vaccine uptake. All analyses were conducted using SAS version 9.4 (SAS Inc., Cary, $\mathrm{NC})$.

\section{Results}

In total, 1303 children attended the 18-month health check-up, and data for 1282 children were gathered (participation rate 98.4\%). Of these children, 664 (52.0\%) were boys. Table 1 shows parents' perceptions and factors possibly related to rotavirus vaccine uptake. We found that $73 \%$ of parents believed RVGE was a serious disease, $66 \%$ believed rotavirus vaccine was effective, $36 \%$ worried about adverse reactions to the rotavirus vaccine, and most (90\%) thought that the rotavirus vaccine was expensive. Parents were more likely to have received a recommendation from a pediatrician to vaccinate their child for rotavirus than from an obstetric doctor. Parents were more likely to get information from city papers than from magazines or the Internet. An analysis of socioeconomic factors showed that about
$60 \%$ of children lived in households with four or more members and two siblings. More fathers than mothers had a university-level education. About $70 \%$ of mothers were employed, and about $40 \%$ of families had an annual income lower than $14,000,000$. About $10 \%$ of children were born weighing less than $2500 \mathrm{~g}$, about $30 \%$ had any primary diseases, and about $60 \%$ used daycare services.

Among the 1282 participating children, 935 had received at least one dose of rotavirus vaccine, giving a proportion of self-reported rotavirus vaccine uptake of $72.9 \%$. However, the vaccination status for 14 children (1.5\%) was not recorded in their maternal and child health handbook. After excluding these 14 children, the record-confirmed rotavirus vaccine uptake was 921 (of 1268 children), giving a proportion of record-confirmed rotavirus vaccine uptake of $72.6 \%$. Among these 921 children, 565 (61.3\%) were vaccinated with Rotarix ${ }^{\oplus} ; 561$ were fully vaccinated and 4 received only one dose. Similarly, of the $356(38.7 \%)$ children that were vaccinated with RotaTeq $^{\oplus}, 351$ were fully vaccinated and five children received two doses. Regarding other self-paid vaccines, 669 children received the mumps vaccine and 625 received the influenza vaccine, meaning that the proportions of record-confirmed vaccine uptake were 52.2 and $49.3 \%$ for mumps and influenza, respectively.

Table 2 shows determinants influencing rotavirus vaccine uptake. In the crude model, parents' belief that RVGE was serious and that the vaccine was effective, pediatricians' recommendation, parental education level, information about rotavirus vaccine from city papers/ magazines/the Internet, and the first child were associated with higher rotavirus vaccine uptake. Larger numbers of household members and siblings, mother's age < 30 years and lower household income were associated with decreased rotavirus vaccine uptake. In the multivariate model, parents' belief that RVGE was serious and vaccination was effective, pediatricians' recommendation, information about rotavirus vaccine from city papers, and mother's higher education level were associated with increased vaccine uptake. However, lower household income was associated with decreased vaccine uptake (adjusted OR: 0.66; 95\%CI: 0.49-0.90). Regarding determinants influencing the self-paid uptake of other vaccines, father's higher educational level was correlated with increased uptake of both mumps and influenza vaccines, whereas larger number of siblings was associated with decreased uptake of these vaccines. A lower household income and mother's age $<30$ years were associated with decreased mumps vaccine uptake; the adjusted ORs for lower household income and mother's age $<30$ years were 0.67 (95\%CI: 0.52-0.87) and 0.60 (95\%CI: 0.44-0.81), respectively. However, these factors were not associated with influenza vaccine uptake. (Additional File 1). 
Table 1 Parents' perceptions and factors potentially related to rotavirus vaccine uptake $(n=1282)$

\begin{tabular}{|c|c|c|c|}
\hline & Agree $n,(\%)$ & Disagree $n,(\%)$ & $\begin{array}{l}\text { Uncertain } \\
n,(\%)\end{array}$ \\
\hline \multicolumn{4}{|l|}{ Perception } \\
\hline I believe that RVGE is a serious disease & $936(73.0)$ & $89(6.9)$ & $257(20.0)$ \\
\hline I believe that the rotavirus vaccination is effective & $846(66.0)$ & $45(3.5)$ & $391(30.5)$ \\
\hline I worry about adverse reactions to the rotavirus vaccine & $455(35.5)$ & $601(46.9)$ & $226(17.6)$ \\
\hline \multirow[t]{2}{*}{ I think that the rotavirus vaccine is expensive } & 1149 (89.6) & $122(9.5)$ & $11(0.9)$ \\
\hline & Yes $n,(\%)$ & No $n,(\%)$ & Missing $n,(\%)$ \\
\hline \multicolumn{4}{|l|}{ Recommendation } \\
\hline Obstetric doctor recommended the rotavirus vaccine & $125(9.8)$ & $1150(89.7)$ & $7(0.5)$ \\
\hline Pediatrician recommended the rotavirus vaccine & $579(45.2)$ & $696(54.3)$ & $7(0.5)$ \\
\hline I read information about rotavirus vaccine in a city paper & $838(65.4)$ & $436(34.0)$ & $8(0.6)$ \\
\hline I read information about rotavirus vaccine in magazines and on the Internet & $478(37.3)$ & $797(62.2)$ & $7(0.5)$ \\
\hline \multicolumn{4}{|l|}{ Socioeconomic status } \\
\hline Household members $\geq 4$ & $765(59.7)$ & $517(40.3)$ & \\
\hline Siblings $\geq 2$ & $712(55.5)$ & $570(44.5)$ & \\
\hline Father's age $<30$ years & $214(16.7)$ & $1033(80.6)$ & $35(2.7)$ \\
\hline Mother's age $<30$ years & $290(22.6)$ & $987(77.0)$ & $5(0.4)$ \\
\hline Father's education level $\geq$ university & $700(54.6)$ & $582(45.4)$ & \\
\hline Mother's education level $\geq$ university & $454(35.4)$ & $828(64.6)$ & \\
\hline Mother has job & $878(68.5)$ & $404(31.5)$ & \\
\hline Household income below $\backslash 4,000,000$ & $470(36.7)$ & $812(63.3)$ & \\
\hline \multicolumn{4}{|l|}{ Children's characteristics } \\
\hline Birth weight < $2500 \mathrm{~g}$ & $116(9.0)$ & $1166(91.0)$ & \\
\hline First child & $601(46.7)$ & $675(52.6)$ & $6(0.5)$ \\
\hline Have primary diseases & $360(28.1)$ & $871(67.9)$ & $51(4.0)$ \\
\hline Daycare use & $714(55.6)$ & $529(41.3)$ & $39(3.0)$ \\
\hline \multicolumn{4}{|l|}{ Self-paid vaccine uptake } \\
\hline Rotavirus vaccine & $921(71.8)$ & $347(27.1)$ & $14(1.1)$ \\
\hline Mumps vaccine & $679(53.0)$ & $587(45.8)$ & $16(1.2)$ \\
\hline Influenza vaccine & $645(50.3)$ & $629(49.1)$ & $8(0.6)$ \\
\hline
\end{tabular}

RVGE rotavirus gastroenteritis

Table 3 lists reasons for parents not vaccinating their children for rotavirus $(n=347)$. The most common reason was "Rotavirus vaccine is not included in the NIP" ( $n=129,37.3 \%)$, followed by "Parents have to pay for uptake" ( $\mathrm{n}=129,30.4 \%)$. Among 105 parents who said they did not vaccinate because of the cost, 44 (41.9\%) parents might have vaccinated if the vaccine was free and $52(49.5 \%)$ might have vaccinated if it was less than 15000 (Additional File 2).

Information about household income was available for 991 of the 1282 participants. The estimated midpoint income for the upper open-ended category was 19,272,912 (Additional File 3). After excluding participants with missing data for number of household members and siblings, we used data for 990 participants to calculate household equivalent income and relative poverty rate. The median household equivalent income (using the per square root scale) was $\backslash 2,886,751$. The median household equivalent income was significantly higher among those who were vaccinated $(\backslash 2,886,571)$ than those who were unvaccinated $(\backslash 2500,00)(P<0.05)$. The poverty line, which was half of the median household equivalent income, was estimated as $\backslash 1,443,375 ; 65$ participants (6.6\%) were defined as having relative poverty.

Table 4 shows relative poverty and self-paid vaccine uptake status using complete data. Relative poverty status was associated with decreased rotavirus vaccine uptake, even after adjusting for parents' education level and other possible influencing factors (adjusted 
Table 2 Parents' perceptions of rotavirus vaccine, rotavirus gastroenteritis, recommendation for vaccination, socioeconomic status, and children's characteristics by rotavirus vaccine uptake $(n=1268)$

\begin{tabular}{|c|c|c|c|c|c|}
\hline & $\begin{array}{l}\text { Vaccinated } \\
(n=921)\end{array}$ & $\begin{array}{l}\text { Unvaccinated } \\
(n=347)\end{array}$ & $\begin{array}{l}\text { Crude OR } \\
(95 \% \mathrm{Cl})\end{array}$ & $\begin{array}{l}\text { Model } 1 \\
\text { aOR }^{\mathrm{a}} \\
(95 \% \mathrm{Cl})\end{array}$ & $\begin{array}{l}\text { Model } 2 \\
\text { aOR }^{\mathrm{b}} \\
(95 \% \mathrm{Cl})\end{array}$ \\
\hline \multicolumn{6}{|l|}{ Perception } \\
\hline I believe that RVGE is a serious disease & $738(80.1 \%)$ & $184(53.0 \%)$ & $\begin{array}{l}3.59 \\
(2.75-4.69)\end{array}$ & N/A & $2.75(2.01-3.76)$ \\
\hline I believe that the rotavirus vaccination is effective & $720(78.2 \%)$ & $115(33.1 \%)$ & $\begin{array}{l}7.27 \\
(5.53-9.56)\end{array}$ & N/A & $5.66(4.20-7.63)$ \\
\hline I worry about adverse reactions to the rotavirus vaccine & $333(36.2 \%)$ & $116(33.4 \%)$ & $\begin{array}{l}1.12 \\
(0.87-1.46)\end{array}$ & N/A & \\
\hline I think that the rotavirus vaccine is expensive & $829(90.0 \%)$ & $309(89.1 \%)$ & $\begin{array}{l}1.06 \\
(0.70-1.61)\end{array}$ & N/A & \\
\hline \multicolumn{6}{|l|}{ Recommendation } \\
\hline Obstetric doctor recommended the rotavirus vaccine & $99(10.8 \%)$ & $25(7.2 \%)$ & $\begin{array}{l}1.55 \\
(0.98-2.45)\end{array}$ & N/A & \\
\hline Pediatrician recommended the rotavirus vaccine & $462(50.2 \%)$ & $108(31.1 \%)$ & $\begin{array}{l}2.23 \\
(1.72-2.90)\end{array}$ & N/A & $2.04(1.50-2.78)$ \\
\hline I read information about rotavirus vaccine in a city papers & $642(69.7 \%)$ & $185(53.3 \%)$ & $\begin{array}{l}1.99 \\
(1.55-2.57)\end{array}$ & N/A & $1.77(1.30-2.41)$ \\
\hline $\begin{array}{l}\text { I read information about rotavirus vaccine in magazines and on the } \\
\text { Internet }\end{array}$ & $382(41.5 \%)$ & $90(26.0 \%)$ & $\begin{array}{l}2.03 \\
(1.54-2.67)\end{array}$ & N/A & $1.3(0.96-1.83)$ \\
\hline \multicolumn{6}{|l|}{ Socioeconomic status } \\
\hline Household members $\geq 4$ & $449(54.2 \%)$ & $258(74.4 \%)$ & $\begin{array}{l}0.41 \\
(0.31-0.54)\end{array}$ & & \\
\hline Siblings $\geq 2$ & $452(49.1 \%)$ & $252(72.6 \%)$ & $\begin{array}{l}0.36 \\
(0.28-0.48)\end{array}$ & $\begin{array}{l}0.30 \\
(0.22-0.41)\end{array}$ & $0.36(0.26-0.49)$ \\
\hline Father's age $<30$ years & $142(15.8 \%)$ & $68(20.5 \%)$ & $\begin{array}{l}0.73 \\
(0.53-1.00)\end{array}$ & & \\
\hline Mother's age $<30$ years & $192(21.0 \%)$ & 95 (27.4\%) & $\begin{array}{l}0.70 \\
(0.53-0.94)\end{array}$ & $\begin{array}{l}0.73 \\
(0.49-1.09)\end{array}$ & \\
\hline Father's education level $\geq$ university & $541(58.7 \%)$ & $151(43.5 \%)$ & $\begin{array}{l}1.85 \\
(1.44-2.37)\end{array}$ & $\begin{array}{l}1.28 \\
(0.93-1.65)\end{array}$ & \\
\hline Mother's education level $\geq$ university & 377 (40.9\%) & $72(20.8 \%)$ & $\begin{array}{l}2.65 \\
(1.98-3.54)\end{array}$ & $\begin{array}{l}2.00 \\
(1.44-2.78)\end{array}$ & $2.27(1.61-3.20)$ \\
\hline Mother's employment & $631(68.5 \%)$ & $237(68.3 \%)$ & $\begin{array}{l}1.01 \\
(0.77-1.32)\end{array}$ & & \\
\hline Household income below $\backslash 4,000,000$ & $301(32.7 \%)$ & $162(46.7 \%)$ & $\begin{array}{l}0.55 \\
(0.43-0.71)\end{array}$ & $\begin{array}{l}0.61 \\
(0.46-0.80)\end{array}$ & $0.66(0.49-0.90)$ \\
\hline \multicolumn{6}{|l|}{ Children's characteristics } \\
\hline Birth weight < $2500 \mathrm{~g}$ & $82(8.9 \%)$ & $31(8.9 \%)$ & $\begin{array}{l}1.00 \\
(0.65-1.54)\end{array}$ & & \\
\hline First child & $488(53.2 \%)$ & $106(30.7 \%)$ & $\begin{array}{l}2.57 \\
(1.97-3.34)\end{array}$ & & \\
\hline Having primary diseases & $264(29.9 \%)$ & $92(27.6 \%)$ & $\begin{array}{l}1.12 \\
(0.84-1.48)\end{array}$ & & \\
\hline Daycare use & $518(57.9 \%)$ & $187(56.0 \%)$ & $\begin{array}{l}1.08 \\
(0.84-1.39)\end{array}$ & & \\
\hline
\end{tabular}

Cl confidence interval, $O R$ odds ratio, aOR adjusted odds ratio, $R V G E$ rotavirus gastroenteritis

${ }^{\text {a }}$ Adjusted for siblings ( $\geq 2$ or $<2$ [reference]), mother's age $(<30$ years or $\geq 30$ [reference]), father's educational level $\geq$ university (yes/no [reference]), mother's

educational level $\geq$ university (yes/no [reference]), and household income below $\backslash 4,000,000$ (yes/no [reference]).

${ }^{\mathrm{b}}$ Further adjusted for perceptions of RVGE, vaccine effectiveness, pediatrician's recommendation, and information from city papers, magazines, and the Internet 
Table 3 Reasons for not vaccinating children $(n=347)$

\begin{tabular}{lll}
\hline Rotavirus vaccine is not included national immunization program & $\mathbf{1 2 9}$ & $\mathbf{( 3 7 . 3 \% )}$ \\
\hline Parents have to pay up to $\backslash 30,000$ (approximately US \$300) for uptake & 105 & $(30.4 \%)$ \\
Suspicious about the vaccine's effectiveness & 20 & (5.8\%) \\
Worry about adverse reactions & 15 & 14 \\
Nobody recommended & 11 & $(4.3 \%)$ \\
Missed the opportunity & 11 & $(3.1 \%)$ \\
I don't think that RVGE is serious & 8 & $(3.2 \%)$ \\
I did not know about the rotavirus vaccine & 6 & $(2.3 \%)$ \\
Rotavirus vaccine is not necessary, because our child does not use daycare. & 28 & $(1.7 \%)$ \\
Others & & $(8.1 \%)$ \\
\hline
\end{tabular}

RVGE rotavirus gastroenteritis

OR: 0.49, 95\%CI: 0.26-0.90). Relative poverty was also associated with decreased mumps vaccine uptake (crude OR: 0.49, 95\%CI: 0.29-0.81), although this correlation was not significant after adjusting for parental educational level. Relative poverty was not correlated with influenza vaccine uptake.

\section{Discussion}

To our knowledge, this was the first study from Asia to assess self-paid rotavirus vaccine uptake status and determinants of vaccine uptake. Although the rotavirus vaccine is currently not included in the NIP and its cost (including doctors' technical fee) for full course vaccination is considered expensive in Japan, vaccine coverage in Kanazawa was estimated at $72.9 \%$. Rotavirus vaccine uptake was associated with parental belief that RVGE was serious and vaccination was effective, recommendation from a pediatrician, information about rotavirus vaccine from city papers, and higher mother's age and higher education level. However, lower household income and relative poverty were associated with decreased rotavirus vaccine uptake, even after adjusting for other determinants.
In terms of the influence of socioeconomic factors on rotavirus vaccination, ecological studies suggest that the most deprived areas have the lowest coverage and higher rates of hospitalization for acute gastroenteritis caused by rotavirus [24, 34, 35]. However, ecological studies were not able to evaluate socioeconomic factors and vaccine uptake with consideration of the influence of parental perceptions, recommendations received, and other individual-level determinants. Although some crosssectional studies evaluated the influence of socioeconomic factors and other determinants on rotavirus vaccine uptake [10, 36, 37], few studies evaluated household income and vaccine uptake $[10,36]$. MacDonald et al. conducted a retrospective population-based cohort study of Canadian children born between January 1, 2008 and December 31, 2013, and found that income had a strong influence in urban areas, but not in rural regions where coverage was lower overall [37]. Our results support the idea that household income influences self-paid vaccination uptake in areas where vaccination coverage is high, even after adjusting for other determinants.

The pivotal point of this study was that we evaluated relative poverty and self-paid vaccine uptake. Relative

Table 4 Relative poverty status and self-paid vaccine uptake $(n=990)$

\begin{tabular}{|c|c|c|c|c|c|}
\hline & Vaccinated & Unvaccinated & Crude OR $(95 \% \mathrm{Cl})$ & Model $1^{\mathrm{a}}$ aOR $(95 \% \mathrm{Cl})$ & Model $2^{b}$ aOR $(95 \% \mathrm{Cl})$ \\
\hline \multicolumn{6}{|c|}{ Rotavirus vaccine } \\
\hline Not poverty & 700 & 225 & 1.00 (reference) & 1.00 (reference) & 1.00 (reference) \\
\hline Poverty & 35 & 30 & $0.38(0.23-0.62)$ & $0.48(0.29-0.81)$ & $0.49(0.26-0.90)$ \\
\hline \multicolumn{6}{|c|}{ Mumps virus vaccine } \\
\hline Not poverty & 521 & 404 & 1.00 (reference) & 1.00 (reference) & \\
\hline Poverty & 25 & 40 & $0.49(0.29-0.81)$ & $0.60(0.35-1.02)$ & \\
\hline \multicolumn{6}{|l|}{ Influenza vaccine } \\
\hline Not poverty & 470 & 455 & 1.00 (reference) & 1.00 (reference) & \\
\hline Poverty & 26 & 39 & $0.65(0.40-1.13)$ & $0.80(0.47-1.35)$ & \\
\hline
\end{tabular}

$O R$ odds ratio, $a O R$ adjusted odds ratio, $\mathrm{Cl}$ confidence interval

a Adjusted for parents' education level $\geq$ university (yes/no [reference])

${ }^{b}$ Further adjusted for perceptions of RVGE, vaccine effectiveness, pediatrician's recommendation, and information from city papers, magazines, and the Internet 
poverty is reported to be significantly associated with child health and wellbeing [21]. According to the Comprehensive Survey of Living Conditions conducted by Japan's Ministry of Health, Labour and Welfare, the relative poverty rate of children in 2015 was 13.9\%, which was 14th highest among 35 OECD countries [22]. Therefore, evaluations of relative poverty and child health-related issues in Japan are important. To our knowledge, this is the first study to show that relative poverty was associated with decreased rotavirus vaccine uptake. Conversely, the uptake of other self-paid vaccines (mumps and influenza) was not correlated with relative poverty. The higher cost of rotavirus vaccine compared with other self-paid vaccines may explain this discrepancy. About one-third of parents of unvaccinated children said they did not get the rotavirus vaccine for their children because of the cost. Therefore, a rotavirus vaccination subsidy for children with relative poverty or universal vaccination may improve vaccine uptake. Fortunately, rotavirus vaccine will be included in the NIP in Japan from October 2020, meaning that the influence of relative poverty will no longer be a reason for nonvaccination.

Consistent with previous reports $[9,10,36-39]$, rotavirus vaccine uptake was positively associated with parental awareness of RVGE severity and confidence in rotavirus vaccine effectiveness, mother's age and educational level. In contrast to a previous report, we found that awareness of safety was not associated with uptake [40]. Regarding vaccine safety, less than $40 \%$ of parents worried about adverse reactions to rotavirus vaccine, although there is a known small risk for intussusception after first dose vaccine [41]. This may indicate that parental decisions regarding vaccination may depend on their knowledge and information about RVGE and rotavirus vaccine, including effectiveness and safety. In this study, recommendation from a pediatrician and information from city papers were associated with rotavirus vaccine uptake. Because childhood vaccines are administered at pediatric clinics in Japan, the role of pediatricians in providing information and recommendation for rotavirus vaccine is important to achieve high coverage.

This study had some limitations. First, we conducted this study in an urban area of Japan and did not include a rural area; therefore, study participants are unlikely to be representative of all Japanese children. The relative poverty rate in this study was $6.6 \%$, which was lower than that for all of Japan (15.7\%) in 2016. The low relative poverty rate in this area might have influenced vaccine coverage and determinants. Additionally, convenience of access to vaccination may differ between urban and rural areas. Geographical accessibility is a factor that influences vaccine hesitancy [42]. Further studies in rural areas are needed to clarify this point. Second, there is potential for recall bias in parents' perceptions and receiving recommendation because those items were measured after vaccination. However, we ascertained vaccination status from the maternal and child health handbook, and questions relating to current socioeconomic factors were answered. Therefore, we consider that the correlation between self-paid vaccine uptake and socioeconomic factors was not affected by recall bias.

\section{Conclusions}

This study revealed that parental socioeconomic status, especially relative poverty, was associated with decreased uptake of self-paid rotavirus vaccine in Japan, which is a high-income country with high vaccination coverage. Increasing vaccination coverage requires inclusion of rotavirus vaccine in the NIP or provision of a subsidy for children in relative poverty. Additionally, recommendation for and information about rotavirus vaccine from pediatricians or city offices is necessary to positively influence parents' vaccination decisions, even after introducing rotavirus vaccine into the NIP.

\section{Supplementary information}

Supplementary information accompanies this paper at https://doi.org/10. 1186/s12879-020-05424-6.

Additional file 1. Socioeconomic status and characteristics of children by self-paid vaccine uptake

Additional file 2. Affordable cost of a full vaccination course among parents who did not vaccinate their children because of the high cost

Additional file 3. Household income categories and their medians

\section{Abbreviations}

Cl: Confidence interval; NIP: National Immunization Program;

OECD: Organisation for Economic Co-operation and Development; OR: Odds ratio; RVGE: Rotavirus gastroenteritis; WHO: World Health Organization

\section{Acknowledgements}

We thank Audrey Holmes, MA, from Edanz Group (www.edanzediting.com/ ac) for editing a draft of this manuscript.

\section{Authors' contributions}

Designed project: MH, RK, and YH. Collected samples: MH, KA and RK. Analyzed data: MH, MK. Generated figures and tables: MH. Wrote manuscript: $\mathrm{MH}$. The authors read and approved the final manuscript.

\section{Funding}

This study was supported by a research grant for Research on Emerging and Re-emerging Infectious Diseases, Health and Labour Science Research Grants from the Ministry of Health, Labour and Welfare, Japan (H29-Shinko-Shitei003, H30-Shinko-Shitei-003, H31-Shinko-Shitei-003, 20HA2001). The funding body had no role in the design of the study and collection, analysis, and interpretation of data and in writing the manuscript.

Availability of data and materials

The datasets used and/or analysed during the current study are available from the corresponding author on reasonable request. 


\section{Ethics approval and consent to participate}

This study was approved by the Institutional Review Board associated with Saga University (No. 30-33), which conformed to the ethical guidelines of the Helsinki Declaration. Written informed consent was obtained for the guardians of all participants.

\section{Consent for publication}

Not applicable since there are no details, images, or videos relating to an individual person.

\section{Competing interests}

Megumi Hare received lecture fees from GlaxoSmithKline/JapanVaccine, Merck Sharp and Dohme, and Sanofi Pasteur Inc. All other authors have no conflicts of interest relevant to this article to disclose.

\section{Author details}

'Department of Preventive Medicine, Faculty of Medicine, Saga University, 5-1-1 Nabeshima, Saga 849-8501, Japan. ${ }^{2}$ Health Affairs Department, Kanazawa City, 1-1-1 Hirosaka, Kanazawa, Ishikawa 920-8577, Japan. ${ }^{3}$ Department of Pediatrics, Faculty of Medicine, Saga University , 5-1-1 Nabeshima, Saga 849-8501, Japan. ${ }^{4}$ Department of Health Care Policy and Health Economics, Faculty of Medicine, University of Tsukuba, 1-1-1 Tenmoudai, Tsukuba, Ibaraki 305-8577, Japan. ${ }^{5}$ College of Healthcare Management, 960-4, Takayanagi, Setaka-machi, Miyama-shi, Fukuoka 835-0018, Japan. ${ }^{6}$ Clinical Epidemiology Research Center, Medical Co. LTA, 3-5-1 Kashii-Teriha Higashi-ku, Fukuoka 813-0017, Japan.

Received: 27 November 2019 Accepted: 15 September 2020 Published online: 29 September 2020

\section{References}

1. Collaborators GBDDD. Estimates of the global, regional, and national morbidity, mortality, and aetiologies of diarrhoea in 195 countries: a systematic analysis for the global burden of disease study 2016. Lancet Infect Dis. 2018;18:1211-28.

2. Rotavirus vaccines. WHO position paper - January 2013. Wkly Epidemiol Rec. 2013;88:49-64.

3. Ruiz-Palacios GM, Perez-Schael I, Velazquez FR, Abate H, Breuer T, Clemens SC, et al. Safety and efficacy of an attenuated vaccine against severe rotavirus gastroenteritis. N Engl J Med. 2006:354:11-22.

4. Vesikari T, Matson DO, Dennehy P, Van Damme P, Santosham M, Rodriguez Z, et al. Safety and efficacy of a pentavalent human-bovine (WC3) reassortant rotavirus vaccine. N Engl J Med. 2006:354:23-33.

5. Ibrahim F, Sharaf El-Din MK, El-Deen AK, Shimizu K. A new HPLC-DAD method for the concurrent determination of hydroquinone, hydrocortisone acetate and Tretinoin in different pharmaceuticals for Melasma treatment. J Chromatogr Sci. 2019;57:495-501.

6. World Health Organization. Summary presentation of routine immunization key indicators; 2018. Available at <http://www.who.int/entity/immunization/ monitoring_surveillance/SlidesGloballmmunization.pptx?ua=1>.

7. Murphy TV, Gargiullo PM, Massoudi MS, Nelson DB, Jumaan AO, Okoro CA et al. Intussusception among infants given an oral rotavirus vaccine. N Engl J Med. 2001;344:564-72.

8. Patel MM, Janssen AP, Tardif RR, Herring M, Parashar UD. A qualitative assessment of factors influencing acceptance of a new rotavirus vaccine among health care providers and consumers. BMC Pediatr. 2007;7:32.

9. MacDougall DM, Halperin BA, Langley JM, MacKinnon-Cameron D, Li L, Halperin SA, et al. Knowledge, attitudes, beliefs, and behaviors of parents and healthcare providers before and after implementation of a universal rotavirus vaccination program. Vaccine. 2016;34:687-95.

10. Vassiliki P, loanna K, Artemis V, Eleni K, Aglaia Z, Attilakos A, et al. Determinants of vaccination coverage and adherence to the Greek national immunization program among infants aged 2-24 months at the beginning of the economic crisis (2009-2011). BMC Public Health. 2014;14:1192.

11. Araki K, Hara M, Shimanoe C, Nishida Y, Matsuo M, Tanaka K. Case-control study of rotavirus vaccine effectiveness compared to test-negative controls or hospital controls. J Epidemiol. 2018

12. Araki K, Hara M, Tsugawa T, Shimanoe C, Nishida Y, Matsuo M, et al. Effectiveness of monovalent and pentavalent rotavirus vaccines in Japanese children. Vaccine. 2018;36:5187-93.
13. Fujii $Y$, Noguchi A, Miura S, Ishii H, Nakagomi T, Nakagomi $O$, et al. Effectiveness of rotavirus vaccines against hospitalisations in Japan. BMC Pediatr. 2017;17:156

14. Morioka I, Kamiyoshi N, Nishiyama M, Yamamura T, Minamikawa S, Iwatani $S$, et al. Changes in the numbers of patients with acute gastroenteritis after voluntary introduction of the rotavirus vaccine in a Japanese children's primary emergency medical center. Environ Health Prev Med. 2017;22:15

15. Kobayashi M, Adachi N, Miyazaki M, Tatsumi M. Decline of rotavirus-coded hospitalizations in children under 5 years: a report from Japan where rotavirus vaccines are self-financed. Vaccine. 2018;36:2727-32.

16. Yoshikawa T, Matsuki T, Sato K, Mizuno M, Shibata M, Hasegawa S, et al. Impact of rotavirus vaccination on the burden of acute gastroenteritis in Nagoya city, Japan. Vaccine. 2018;36:527-34.

17. Shono A, Kondo M. Factors that affect voluntary vaccination of children in Japan. Vaccine. 2015;33:1406-11.

18. Hoshi SL, Kondo M, Okubo I. Economic evaluation of routine infant rotavirus immunisation program in Japan. Hum Vaccin Immunother. 2017;13:1115-25.

19. Deen J, Lopez AL, Kanungo S, Wang XY, Anh DD, Tapia M, et al. Improving rotavirus vaccine coverage: can newer-generation and locally produced vaccines help? Hum Vaccin Immunother. 2018:14:495-9.

20. Japan medical association. Vaccination price in Japan; 2013. https://www.mhlw go.jp/file/05-Shingikai-10601000-Daijinkanboukouseikagakuka-Kouseikagakuka/ 0000029884_1_1_2_2.pdf. (in Japanese). Accessed 23 Sept 2020.

21. Emerson E. Relative child poverty, income inequality, wealth, and health. JAMA. 2009;301:425-6.

22. The Comprehensive Survey of Living Conditions, the Ministry, Labour, and Welfare in Japan, 2018.

23. Hungerford D, Macpherson P, Farmer $S$, Ghebrehewet $S$, Seddon D, Vivancos $R$, et al. Effect of socioeconomic deprivation on uptake of measles, mumps and rubella vaccination in Liverpool, UK over 16 years: a Iongitudinal ecological study. Epidemiol Infect. 2016;144:1201-11.

24. Hungerford D, Vivancos R, Read JM, Iturriza-Gomicronmara M, French N, Cunliffe NA. Rotavirus vaccine impact and socioeconomic deprivation: an interrupted time-series analysis of gastrointestinal disease outcomes across primary and secondary care in the UK. BMC Med. 2018;16:10.

25. Akashi H, Ishioka M, Hagiwara A, Akashi R, Osanai Y. Core factors promoting a continuum of care for maternal, newborn, and child health in Japan. Biosci Trends. 2018;12:1-6.

26. Ministry of Health, Labour and Welfare. The Ministry's standard forms for the MCH Handbook (revised January 15, 2002). Tokyo (Japan): Ministry of Health, Labour and Welfare; 2002 [Available from: https://www.mhlw.go.jp/ shingi/2002/01/s0115-2a.html.

27. Annual reports of health and welfare services for children in Kanazawa city, 2018 [Available from: https://www4.city.kanazawa.lg.jp/data/open/cnt/3/25 778/1/2-1.child30.pdf.

28. MacDonald SE, Russell ML, Liu XC, Simmonds KA, Lorenzetti DL, Sharpe H, et al. Are we speaking the same language? An argument for the consistent use of terminology and definitions for childhood vaccination indicators. Hum Vaccin Immunother. 2019;15:740-7.

29. Centers for Disease Control and Prevention. Global routine vaccination coverage, 2018. Morbid Mort Wkly Rep. 2019;68:938-42.

30. Parker RN, Fenwick R. The pareto curve and its utility for open-ended income distribution in survey research. Sorc Forces. 1938;61:872-85.

31. Celeste RK, Bastos JL. Mid-point for open-ended income category and the effect of equivalence scales on the income-health relationship. Rev Saude Publica. 2013:47(Suppl 3):168-71.

32. OECD Income Distribution Database (IDD): Gini, poverty, income, Methods and Concepts. WHAT ARE EQUIVALENCE SCALES? http://www.oecd.org/els/ soc/OECD-Note-EquivalenceScales.pdf. Accessed 23 Sept 2020.

33. Organisation for Economic Co-operation and Development. Growing unequal?: income distribution and poverty in OECD countries. Paris: OECD Publications; 2008.

34. Gimenez Sanchez F, Nogueira EJ, Sanchez Forte M, Ibanez Alcalde M, Cobo $E$, Angulo R, et al. Impact of vaccination uptake on hospitalizations due to rotavirus acute gastroenteritis in 2 different socioeconomic areas of Spain. Hum Vaccin Immunother. 2016;12:1035-9.

35. Orrico-Sanchez A, Lopez-Lacort M, Perez-Vilar S, Diez-Domingo J. Long-term impact of self-financed rotavirus vaccines on rotavirus-associated hospitalizations and costs in the Valencia region, Spain. BMC Infect Dis. 2017;17:267. 
36. Ganczak M, Dmytrzyk-Danilow G, Karakiewicz B, Korzen M, Szych Z. Determinants influencing self-paid vaccination coverage, in 0-5 years old polish children. Vaccine. 2013;31:5687-92.

37. MacDonald SE, Bell CA, Simmonds KA. Coverage and determinants of uptake for privately funded rotavirus vaccine in a Canadian birth cohort, 2008-2013. Pediatr Infect Dis J. 2016;35:e177-9.

38. Dube E, Bettinger JA, Hal perin B, Bradet R, Lavoie F, Sauvageau C, et al. Determinants of parents' decision to vaccinate their children against rotavirus: results of a longitudinal study. Health Educ Res. 2012;27:1069-80

39. Doherty E, Walsh B, O'Neill C. Decomposing socioeconomic inequality in child vaccination: results from Ireland. Vaccine. 2014;32:3438-44.

40. Veldwijk J, Lambooij MS, Bruijning-Verhagen PC, Smit HA, de Wit GA. Parental preferences for rotavirus vaccination in young children: a discrete choice experiment. Vaccine. 2014;32:6277-83.

41. Carlin JB, Macartney KK, Lee KJ, Quinn HE, Buttery J, Lopert R, et al. Intussusception risk and disease prevention associated with rotavirus vaccines in Australia's National Immunization Program. Clin Infect Dis. 2013; 57:1427-34.

42. Bedford H, Attwell K, Danchin M, Marshall H, Corben P, Leask J. Vaccine hesitancy, refusal and access barriers: the need for clarity in terminology Vaccine. 2018;36:6556-8.

\section{Publisher's Note}

Springer Nature remains neutral with regard to jurisdictional claims in published maps and institutional affiliations.

Ready to submit your research? Choose BMC and benefit from:

- fast, convenient online submission

- thorough peer review by experienced researchers in your field

- rapid publication on acceptance

- support for research data, including large and complex data types

- gold Open Access which fosters wider collaboration and increased citations

- maximum visibility for your research: over $100 \mathrm{M}$ website views per year

At $\mathrm{BMC}$, research is always in progress.

Learn more biomedcentral.com/submissions 